
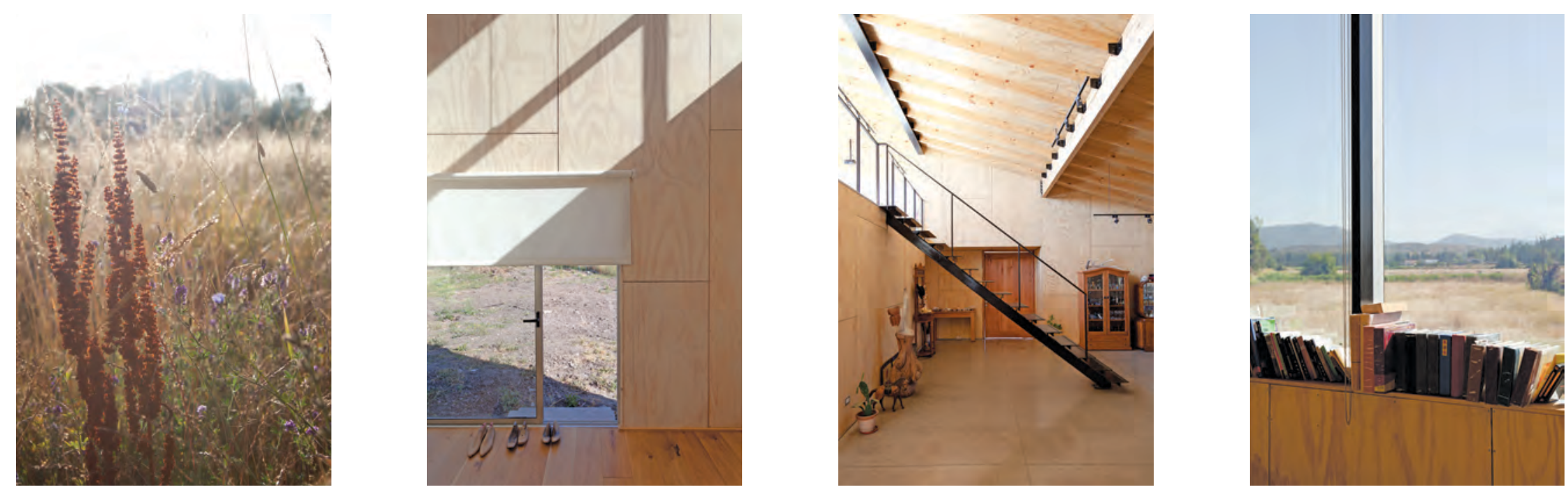

Nicolás Rupcich | Artista visual, Rupcich Estudio. Licenciado en Artes Visuales, Universidad

Finis Terrae, 2003; Magíster en Artes Visuales, Universidad de Chile, 2006 y Diplomado CrossMedia, Academia Mac-PC, 2006. Su trabajo se concentra en la fotografía, el video y los nuevos medios; además de su obra independiente, ha realizado distintos encargos de fotografía y video para arquitectos. Su trabajo ha sido expuesto en Berlín, Santiago, Kassel, Beijing, Sao Paulo y recientemente en Espace Culturel Louis Vuitton en París. Emilio Marín | Profesor, Universidad de Chile. Arquitecto, Universidad de Chile, 1998 y estudios de Magíster en Artes Visuales, Universidad de Chile. En 2005 crea su oficina de arquitectura y en 2008 , jun to a Diego Córdova, funda la editorial independiente Public Library, dedicada a crear y a publicar materia propio y de artistas. En 2009 fue seleccionado por la revista ICON como uno de los veinte arquitectos en el mundo que están construyendo el futuro. $\mathrm{Ha}$ ejercido la docencia en las Universidades Diego Portales y Andrés Bello.
Este registro fotográfico de una obra reciente en las afueras de Santiago construye un pequeño universo doméstico donde, por medio de la arquitectura, se encuentran el territorio, los ritos de la vida familiar y posesiones acumuladas en el tiempo.

Palabras clave: Arquitectura - Chile, fotografía Chile, atmósferas, cotidiano.

A set of photographs from a recently completed house in the outskirts of Santiago tells a story about a tiny domestic universe where territory, the rituals of life at home and possessions collected through time meet in architecture.

Keywords: Architecture - Chile, photography - Chile, atmospheres, everyday life.

\section{Bibliografía sugerid}

AA.VV. Chili, l'envers du décor. Centre Culturel Louis Vuitton, París, 2010.

MARÍN, Emilio. “Paseo Altamirano”. ARQ № 73 ,

Valparaíso. Ediciones ARO, Santiago, diciembre de 2009.

KLANTEN, Robert; MOLLARD, Adeline y Matthias HÜBNER. Behind the zines. Self publishing culture. Die Gestalten Verlag GmbH \& Co. KG, Berlín, 2011.

http://www.rupcich.cl

http://www.emiliomarin.c

Otras fotografías de la casa Santa Julia están disponibles para los suscriptores ARQ en edicionesarq.cl

\title{
FOTOGRAFÍAS DE LA CASA SANTA JULIA NICOLÁS RUPCICH
}



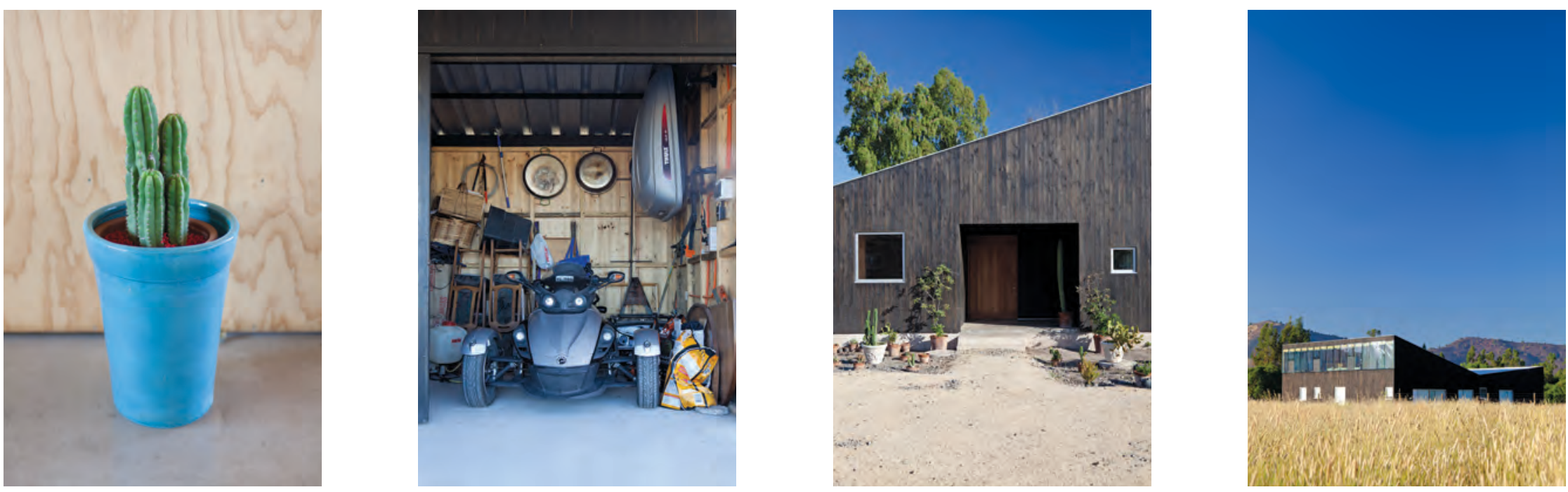

La casa Santa Julia está construida en el valle central de Chile, a una hora de viaje en automóvil al sur de Santiago, en un terreno dentro de un condominio colindante con una parcela destinada al cultivo de hortalizas. Los propietarios de la vivienda tienen una vida social muy activa, que incluye tanto a la propia familia como a grupos de amigos cercanos; por esto los espacios de encuentro -estar, comedor, cocina, altillo y terraza exterior- son de gran tamaño.

Todos ellos se conectan visual y espacialmente para conformar un gran ámbito continuo de expansión social. Las puertas y ventanas correderas del primer piso se diseñaron para permitir la conexión del espacio interior y el espacio exterior; en verano, cocina, estar y terraza pueden transformarse en un único y holgado espacio de reunión.

Los dormitorios, en cambio, funcionan como entidades autónomas e individuales, que toman distancia de los espacios de activi- dad social a través de un espacio intermedio que, en cada caso, los relaciona con el resto de la casa. El sistema permite que actividades públicas y privadas se puedan desarrollar simultáneamente dentro de un mismo lugar.

Los dos ámbitos interiores, social y privado, comparten un único techo de altura variable. La verticalidad del espacio del dormitorio principal acusa la magnitud de la casa, situación que se vuelve a repetir en la cocina, en el estar y en el altillo, cada vez ofreciendo una perspectiva diferente tanto de la vida interior como de la extensión del campo (ЕмM). ARQ

Fotografías de LA CASA SANTA JULIA | Proyecto de Emilio Marín. Melipilla, Chile, 2011. | Arquitecto asociado: Juan Carlos Huerta. | Superficie construida: 350 $\mathrm{m}^{2}$. | Mandante: Álvaro Pérez. | Constructor: Alfio Secchi. | Fotografía: Nicolás Rupcich. 